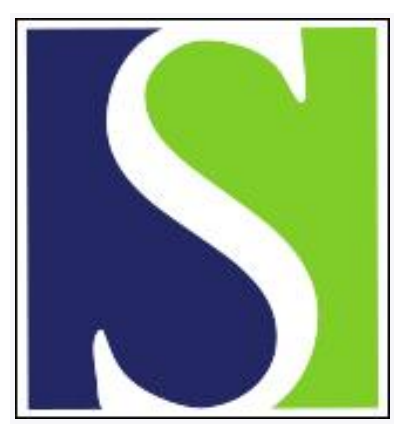

Scand J Work Environ Health 2011;37(5):359-362

https://doi.org/10.5271/sjweh.3185

Published online: 03 Aug 2011, Issue date: Sep 2011

Sickness absence, office types, and advances in absenteeism research

by Steensma $\mathrm{H}$

Affiliation: Department of Social and Organizational Psychology, Leiden University, Leiden, the Netherlands. steensma@fsw.leidenuniv.nl

Refers to the following texts of the Journal: 2011;37(5):376-382

2007;33(3):233-239 2006;32(4):257-269 2006;32(4):253-255

2006;32(1):67-74 2005;31(1):3-14 1996;22(2):108-111

The following articles refer to this text: 2012;38(3):187-192;

2016;42(3):192-200; 2016;42(4):299-308

Key terms: absenteeism; intervention; office building; office type; open-plan office; research method; shared office; sick leave; sickness absence; work environment

This article in PubMed: www.ncbi.nlm.nih.gov/pubmed/21814705

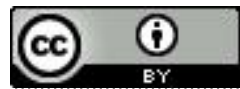




\section{Sickness absence, office types, and advances in absenteeism research}

Sickness absenteeism and work incapacity are major problems in many countries. Employees, employers, and our society suffer from the negative effects of sickness absenteeism. Many governments have developed legislation to encourage organizations to reduce absenteeism and disability rates. Companies have to implement policies on the counseling and reintegration of sick employees. Moreover, many organizations have formulated their own special policies and are doing more than is formally prescribed by law. However, although formal laws and policies may succeed in reducing the rates of absenteeism and occupational disability, they do not offer insight into the mechanisms that explain these rates and the successful reduction of the problems. Such knowledge of explanatory mechanisms is necessary for the development of theory- and evidence-based policies and programs to reduce sickness absence and promote reintegration (1, 2). Many theories have been developed and tested. Most of these theories are a special form of a more general, comprehensive model. Focusing on sickness absenteeism, three general models seem to be most popular: the expected utility model of absenteeism; the stress model; and the organization model (3).

The expected utility model is also known as the decision model of absenteeism. The model assumes that workers have some latitude to decide whether or not they will report sick. The choice to report sick is affected in particular by the subjective probabilities (expectancies) of the possible costs and rewards connected with absenteeism and the subjective values (utilities) of these perceived costs and rewards. If many costs are expected to result from absenteeism, workers will hesitate to report ill. In other words, in such situations there is a high "threshold" (hurdle or barrier) against reporting ill. The core of the general utility model is often connected with other factors, for example, person-bound factors (ie, age, educational level, personality differences), needs, and objective opportunities for people to behave in the way they prefer. These other factors may affect the expectancies and subjective utilities of costs and rewards.

The implications for absenteeism policies based on the decision model are clear: strive for high thresholds against reporting ill and try to lower the threshold to resume work (4). Frequently, such policies combine a reduction of "opportunities" for being absent with a change to the costs and rewards of being absent. However, the model has only good explanatory power in situations where, according to medical standards, there is no real necessity to stay home.

The general occupational stress model focuses on the negative effects of characteristics of the objective work environment (ie, objective stressors), the subjective, "psychological" work environment (ie, the perceived stressors), and the responses and the mental and physical health of workers. The model states that relations between these factors are moderated by the coping abilities of workers and social support.

Stress may originate from a variety of sources (such as work overload, time pressures, technological change, and bullying) and may lead to a variety of reactions at the physiological, psychological, or behavioral level. Long-term effects of chronic stress may include significant and severe health problems, and even death. However, some people are able to tolerate far higher levels of stress than others. Moreover, high quality of social relationships may moderate the effects of organizational stressors. Finally, when confronted with stressful environments, people develop special behaviors or coping strategies to cope, some of which are far more successful in reducing stress than others. Employees' personality factors are also related to their tolerance of stress. The concept of "resilience" might be used to indicate a high ability to tolerate and cope with stress; employees who can deal well with stressful situations are "resilient". They share certain personality characteristics and make use of more successful coping strategies. Disability 
management and vocational rehabilitation programs may profit from this knowledge. In particular, disability management focusing on an individual approach and offering training and exercises to disabled and sick employees could profit from the findings of "resilience research" to make (former) workers more fit for the labor market. Return-to-work strategies based on such training and exercises show promise for returning disabled (and long-term unemployed) employees to work $(5,6)$.

Several theorists assume that a direct relationship exists between perceived stressors and absenteeism. Many researchers believe that there may well exist both a direct and an indirect path via the job dissatisfaction mediator to sickness absenteeism. The stress model lies at the root of two general absenteeism reduction strategies, namely (i) reduction of stressors, and (ii) strengthening of coping abilities. These strategies are frequently combined. Reduction of (occupational) stressors can take several forms: a congenial atmosphere; improved ergonomic conditions; reduced quantitative overload; regular breaks during working hours; redesigned mental tasks to reduce qualitative overload (not having work that is too difficult to do), et cetera. Strengthening coping abilities can also take many forms, for example: medical examinations to ensure that workers are appointed to posts with a task load that fits their abilities; social support from considerate supervisors; fitness programs to improve the health of employees; training and development programs, and so forth.

The organization mode/ pays attention to the rewarding properties of working in an organization. This model is particularly suitable to build a bridge between, on the one hand, the features of organizations and jobs, and on the other, the needs, motives, and behavior of people working in these organizations. The general organization model stresses the importance of, for example, rich job content, autonomy, rewarding aspects of social relations with colleagues and supervisors, the role of fair pay, and the status of the occupation in society. These aspects lead to high satisfaction, strong work motivation, higher general well-being, and - via these mediator variables - better health and lower sickness absenteeism. The implications for absenteeism policy are, in principle, simple. A preventive, structural approach should be followed, mainly based on the redesign of tasks, departments, and organization. In practice, such planned change projects may be plagued by problems such as resistance to change.

Integrated model. The three general models are not mutually exclusive in the sense that only one model is best. Actually, they are complementary since each model explains a different, and often sizeable, portion of the sickness absenteeism. Therefore, they can be combined into an integrated model; it is wise to base absenteeism policy on a mix of ideas inferred from two or more absenteeism models (4).

There are several slightly different variations of each general model. Moreover, some models of work and health combine elements of two (or even all three) general models. Examples are Karasek's well-known job demands-control and demand-control-support models, which combine elements of the stress model with the organization model $(7,8)$. Still, most theories on sickness absence can easily be recognized as a special variation on a general model, and most studies can be categorized as tests of (a variation of) such a general model.

The value of the general models is that they bring a clear structure to the enormous amount of theories and studies on sickness absenteeism. But this does not imply that each time a new research project is planned the starting point should be such a general model. It is particularly useful to study very special aspects of the job and the work environment, since absenteeism is a problem with many possible causes.

A fine example of the value of studying special aspects that are sometimes neglected by psychologists and sociologists is presented in the current issue of the Scandinavian Journal of Work and Environmental Health. I refer here to the article of Pejtersen et al (9). This is one of the few studies that has related the sickness absenteeism of employees to the characteristics of an office's indoor environment. To be sure, not all aspects of indoor environment have been neglected by researchers. For example, indoor air problems and their relations with health problems have become a new research topic for occupational health 
researchers and recently a special issue of SJWEH Supplements was devoted to the relation between indoor environment - in particular indoor air problems - and health problems and productivity (10). But up to now, the associations between type of office and employees' occupational health problems have hardly been studied. Now they are the central research topic of the paper by Pejtersen and his colleagues. To the best of my knowledge, it is the first national population study in which sickness absence is related to the type of office (cellular versus shared with other employees). The analysis is based on a representative sample of Danish inhabitants, and the sample size of the 2403 employees that reported working in offices is impressive. Office workers were divided into four categories according to the type of office in which they worked: cellular (one occupant), shared offices with two occupants; shared offices comprising three to six occupants, and open-plan offices with more than six occupants. Sickness absence was assessed with the self-reported number of sickness absence days in the last year.

The rate ratios for sickness absence in the various office types clearly show that sickness absence was significantly related to the type of office when adjusting for age, gender, socioeconomic status, body mass index, smoking habits, alcohol consumption, and physical activity of employees during their leisure time. The lowest number of sick days was reported by the occupants of cellular offices, while the occupants of open-plan offices (with more than six persons in each office) had on average $62 \%$ more days of sickness absence. The occupants in shared offices (two or three to six occupants) scored in-between. This is an important result. Since many organizations (plan to) use shared and open-plan offices, the results of this study are highly relevant to decision-makers. The present study indicates that employers, employees, and society in general may have to pay a high price for the popularity of shared/open plan offices in the form of greater health problems and more sickness absence. And, of course, this study presents important new information for scientists.

How can the results be explained? The authors suggest five possible explanations for the increased sickness absence in shared and open-plan offices: (i) higher exposure to noise; (ii) lower quality of the ventilation; (iii) higher risks of exposure to viruses; (iv) problems caused by the psychosocial work environment (for example, lack of privacy), and finally (v) perceived lack of autonomy and possible interference by co-workers. Most of these explanations point to specific stressors as a cause of absenteeism.

Of course, the study has some limitations, and the heavy reliance on self-reported data is perhaps the most important weakness. The authors are aware of these weaknesses. So, more research is needed. But it should be stressed that the present study definitely is an important contribution to the field of occupational health and to society in general since the well-being and the health of many employees may profit from the findings.

This study also demonstrates that it is still possible to find surprising new associations between variables and add new topics to be studied by experts in the field of sickness absence. That means scientific progress. It is my firm conviction that we can accelerate advances in our science by paying more attention to a few recent trends and pleas for renewal by some colleagues. I conclude by briefly mentioning some suggestions.

Advances in work and environmental health research. Many studies use a cross-sectional research design with data gathered at the same point in time. Such studies may be very useful, but - for understanding the causal relations between factors at work and health - longitudinal studies are to be preferred. Longitudinal designs make it even possible to distinguish normal causation from reverse and reciprocal causation (11). In many longitudinal studies, traditional methods of multiple regression analysis are used. However, sickness absence data are time dependent, highly skewed, and often clumped at "zero values". Ignoring these features when making statistical inferences may sometimes lead to misguided inferences, and researchers may miss important aspects. So, it seems wise to make a more frequent use of special methods for analyzing such data (12). Analyzing sickness absence with statistical models for survival 
data has much to offer and should be done more frequently. For example, standard methods often underestimate true effect sizes (13). Moreover, social scientists working in the field of occupational health should acquire knowledge of some data analysis techniques that do not belong to the standard repertory of social sciences, but have much value in the analysis of sickness absence data. The use of Markov chain approaches (14) and analysis of receiver operating characteristics (ROC) curves, a technique based on signal detection theory (15), are good examples. Both methods make it possible to detect aspects that may go unnoticed in studies using more conventional research methods.

Finally, in medical science it is a good practice to have several medications available to cure a specific illness. Medicine A might cause side-effects in some patients to whom, therefore, medicine B should be given. The same principle is true when designing interventions to promote occupational health. Such interventions should be based on good theories. Predictions derived from these theories should be tested by advanced research methods. This is not sufficient, though. Implementation of adequate interventions requires knowledge of intervention techniques in organizations. Paying careful attention to the best way of designing and implementing such interventions is a somewhat neglected topic, however, and good evaluation studies are scarce. Action research may solve parts of the problem, but much remains to be done (3). As is so often the case, the final conclusion is that more research is needed.

\title{
References
}

1. Martimo K-P. Reducing sickness absenteeism at the workplace - what to do and how? Scand J Work Environ Health. 2006;32(4):253-255.

2. MacEachen E, Clarke J, Franche R-L, Irvin E; Workplace-Based Return to Work Literature Review Group. Systematic review of the qualitative literature on return to work after injury. Scand J Work Environ Health 2006;32(4):257-69.

3. Steensma H, Van der Vlist R. Action research to reduce sickness absenteeism - a case study. Concepts and Transformation, International Journal of Action Research and Organizational Renewal. 1998;3(3):179-206.

4. Allegro JT, Veerman TJ. Sickness absence. In: Drenth PJD, Thierry H, De Wolff CJ (Eds.). Handboook of work and organizational psychology, 2nd edition. East Sussex: Psychology Press, 1998; pp121-44.

5. Steensma H, Den Heijer M, Stallen V. Research note: effects of resilience training on the reduction of stress and depression among Dutch workers. Int Quart Commun Health Educ. 2006/2007;27(2):145-159.

6 Price H, Van Ryn M, Vinokur A.D. Impact of a preventive job search intervention on the likelihood of depression among the unemployed. J Health Social Behavior. 1992;33:158-167. doi:10.2307/2137253.

7. Karasek RA. Job demands, job decision latitude, and mental strain: Implications for job redesign. Admin Sci Quart. 1979;24:285-308. doi:10.2307/2392498.

8. Karasek RA, Theorell T. Healthy work. Stress, productivity and the reconstruction of working life. New York:Basic Books, 1990.

9. Pejtersen JH, Feveile H, Christensen KB, Burr H. Sickness absence associated with shared and open-plan offices - a national cross sectional questionnaire survey. Scand J Work Environ Health. 2011;37(5):376-382. doi: 10.527/ sjweh.3167.

10. Reijula R, Vainio H, guest editors. International conference on healthy air — better work 2007: selected presentations from the International Conference on Healthy Air-Better Work 2007; 29-31 May 2007; Helsinki, Finland. SJWEH Suppl. 2008;(4):1-86.

11. De Lange AH, Taris TW, Kompier MAJ, Houtman ILD, Bongers PM. Different mechanisms to explain the reversed effects of mental health on work characteristics. Scand J Work Environ Health. 2005;31(1):3-14.

12. Lu X, Leino-Arjas P, Piha K, Aittomäki A, Saastamoinen P, Rahkonen O, Lahelma E. On methodologies for analysing sickness absence data: An insight into a new method. Int J Biological Life Sci. 2011;7(2):101-106.

13. Christensen KB, Andersen PK, Smith-Hansen L, Nielsen ML, Kristensen TS. Analyzing sickness absence with statistical models for survival data. Scand J Work Environ Health. 2007;33(3):233-239.

14. Burdorf A, Jansen P. Predicting the long term course of low back pain and its consequences for sickness absence and associated work disability. Occup. Environ Med. 2006;63(8):522-529. doi:10.1136/oem.2005.019745.

15. Nieuwenhuijsen K, Verbeek JHAM, de Boer AGEM, Blonk RWB, van Dijk FJH. Predicting the duration of sickness absence for patients with common mental disorders in occupational health care. Scand J Work Environ Health. 2006;32 (1):67-74.

\author{
Herman Steensma \\ Department of Social and Organizational Psychology \\ Leiden University, Leiden, the Netherlands \\ [E-mail: steensma@fsw.leidenuniv.nl].
}

